\title{
Smartphones and their role in the modern classroom
}

\author{
Les téléphones intelligents et leur rôle \\ dans la classe du XXI e siècle
}

Research paper with empirical datas

\section{Abstract}

Mobile and wireless technologies have reached such a high level of sophistication that, today, they can be more easily incorporated into teaching and learning processes. The purpose of this paper is to examine the extent to which present-day classes can benefit from the use of smartphones and mobile applications. To this end, a study looked at the experience of 204 ADA University students in the Faculty of General Education over two academic terms in a Writing and Information Literacy course. At the end of the academic year, the students filled out a survey. Descriptive statistics, such as simple percentage mean and standard deviation, were used to analyze the data. The study reveals that smartphone functions like note-taking, photos of the whiteboard and/or smartboard, video recordings, and the WhatsApp application can become an integral part of the modern classroom. The study also suggests that smartphone technology should be widely applied by university teachers/instructors and, in the future, may lead to certain changes in teaching methodology generally.

\section{Key Words}

Innovative methodology; mobile technology; mobile applications; note-taking; reading; smartphones

\section{Résumé}

Les technologies mobiles ont atteint un tel degé de sophistication qu'elles peuvent facilement être incorporées dans les activtés d'enseignement et d'apprentissage. Le but de cet article est d'examiner jusqu'à quel point les salles de classe actuelles peuvent profiter de l'utilisation des téléphones mobiles et de leurs différentes applications. Dans cette optique, nous avons mené une expérience auprès de 204 étudiants de la faculté d'éducation de l'Université ADA, durant deux sessions universitaires, dans le cours intitulé Writing and Information Literacy. À la fin de l'année universitaire, les étudiants ont répondu à une enquête. Les données ont été analysées à l'aide de statistiques descriptives comme le pourcentage moyen et l'écart-type. L'étude révèle que les diverses fonctions du téléphone mo-

(CAuteur(s). Cette œuvre, disponible à https://doi.org/10.18162/ritpu-2018-v15n2-01, est mise à disposition selon les termes de

la licence Creative Commons Attribution 4.0 International http://creativecommons.org/licences/by/4.0/deed.fr 
bile, telles que la prise de notes, la photographie du tableau blanc ou du tableau numérique, l'enregistrement vidéo et l'application WhatsApp peuvent être intégrées à une sale de classe moderne. L'étude suggère aussi que la technologie liée au téléphone mobile pourrait avantageusement être utilisée par les enseignants et les éducateurs, ce qui pourrait contribuer à apporter certaines modifications dans les méthodes d'enseignement.

\section{Mots-clés}

Méthode d'enseignement innovante; technologie mobile; applications mobiles; prise de notes; lecture; téléphone mobile

\section{Introduction}

Over the past decade, technology has achieved tremendous penetration in the educational process and has had a significant impact. While most of those involved in education (e.g., teachers, instructors, lecturers, heads of educational institutions) still reject the unprecedented role of ordinary computers and laptops in the classroom (Mammadova, 2014), more technologically advanced educators believe that mobile learning, or m-learning, can facilitate the teaching process in many ways. Agbatogun (2013), for example, insists that mobile and wireless technologies are evolving rapidly to influence teaching and learning processes. Moreover, applying wireless and mobile technologies in the classroom gives educators and learners unrestricted access to information in terms of location and time without compromising quality in content delivery (Agbatogun, 2013; Wabwoba, Omieno, Simiyu, \& Sisungo, 2011). While other wireless technologies like laptops and personal digital assistants have been shown to significantly affect human behaviour, mobile phone technology, which has become ubiquitous, has done more (Shahriza Abdul Karim, Oyebisi, \& Mahmoud, 2010). Today, m-learning can be defined as "any educational provision where the sole or dominant technologies are handheld or palmtop devices" (Park, Nam, \& Cha,
2012, p. 592). Although the notion of m-learning is a broad one (comprising tablets, iPads, mobile phones, and other portable devices), we will restrict this study to smartphones, which have become the primary personal device of almost all university students. According to Gikas and Grant (2013, as cited in Dukic, Chiu, \& Lo, 2015, p. 546), mobile learning hinges on four major characteristics of the smartphone. These are: continuous access to the Internet, a variety of downloadable applications, communication capability, and a compact size so users can carry the device in a pocket or handbag. Many believe that incorporating technology like mobile phones into the educational system can solve a range of educational problems in a number of ways (Agbatogun, 2013; Mostert \& Quinn, 2009).

Yet even now, when most people, including teachers and students, are so dependent on technology and on smartphones in particular, university faculties have been slow to adopt technology in the classroom, largely due to teachers' beliefs and attitudes (Ruthven \& Hennessy, 2002, as cited in Agbatogun, 2013, p. 335). Most of today's educational institutions have taken a "just say no" approach to the use of personal mobile devices at school, be they cell phones or tablets, such as the popular Apple iPad (Sauers \& Kruse, 2013) or iPhone. One common complaint is that students are distracted during lectures and seminars, lured by the immediacy of social networking and other Internet sites that are disruptive to both teaching and learning. According to Langan et al. (2016), students use laptops not only for note-taking and reading but also to access information, communicate with others, play games, and watch movies. The author has often seen certain teachers/instructors attempt to prevent such distractions in the classroom by collecting students' mobile (smart) phones before the lesson, allowing them to retrieve their devices only when class ends. Additionally, signs prohibiting mobile phones are posted in many classrooms. But as the saying goes, "forbidden fruit is sweet": restrictive measures like collecting smartphones before class and asking students to turn them off or keep them in their pockets or handbags to prevent distraction may simply tempt students, distracting them further. Sauers and 
Kruse (2012) claim that students have always been distracted at school. In other words, it's not the fault of these new devices! According to these scholars, the top sources of distraction are decontextualized instruction, disconnected curriculum, and pointless assignments (Sauers \& Kruse, 2012).

In contrast, some schools have begun to purchase various mobile devices for their students for educational purposes, although allowing pocket assistive technology in schools for student personal use is still quite rare (Sauers \& Kruse, 2012). Hence, the question remains: should educators allow students to use their own handheld technology tools? A significant number of undergraduate students claim to use smartphones and apps to find academic information. They seek out online versions of traditional information sources, such as encyclopedias, dictionaries, translators, or libraries (Reese Bomhold, 2013). Furthermore, Agbatogun (2013) believes that conventional non-interactive technologies, like slides and overhead projectors, PowerPoint presentations, and whiteboards that fail to promote twoway interaction in class no longer meet the needs of twenty-first century teaching and learning. If our major goal is to provide all students with effective and efficient access to barrier-free education (Morse \& Crowe, 2012), we should consider ways to include smartphones in the educational processways that would facilitate, rather than distract from teaching and learning processes.

Thus, the goal of the present study is to investigate how effectively smartphones can be adopted and integrated into the teaching process in order to facilitate teaching and learning between teacher and students $(\mathrm{T} \neg \circledast \mathrm{S})$ and among students $(\mathrm{S} \neg \AA \mathrm{S})$. The study focuses on applications that are available for most smartphones. More specifically, the investigation looked at the experience of students in the Writing and Information Literacy course at ADA University in Azerbaijan. The paper reports on a survey examining undergraduate use of the smartphone application WhatsApp for academic purposes inside and outside the classroom as well as such basic smartphone functions as note-taking, calendar, photos, etc.

\section{Method}

Among the key motivations for conducting this survey was the perceived ambivalent attitude among the author's colleagues regarding the use of mobile phones in the classroom. Many instructors claim that "smartphones distract students from regular classes" and that "before entering class, students should turn their smartphones off." Others contend that smartphones should be actively used in the modern classroom to motivate students and generally facilitate the teaching and learning processes. Thus, to determine just how conducive and helpful smartphone use can be in present-day classes, a number of first-year undergraduate students (20162017) at ADA University were invited to take a survey after a two-term experiment. The research was conducted in the Writing and Information Literacy (Writing 101 and Writing 102) class at the Faculty of General Education of ADA University in Azerbaijan. Both qualitative and quantitative methods of data collection were used for the study. To calculate percentages, the study responses were processed via the Excel program from Google Forms to STATA software. An $R$ package was applied to assess the statistically significant difference in respondents' answers and to calculate the p-value.

\subsection{Participants}

The study population consisted of 204 undergraduate students $(\mathrm{M}=10.05$ years of age, $\mathrm{SD}=2.05$ years of age). Of these participants, 97 (47.8\%) were female and 106 (52.2\%) were male. Although the students attended the same sections of the Writing and Information Literacy class, their academic majors were diverse. Moreover, the respondents were not only from Azerbaijan (192 students) but also from other countries: USA (1 student), Germany ( 1 student), Maldives ( 1 student), Russia (5 students), Turkey (2 students), and Afghanistan (1 student). All participants owned smartphones: 31\% of respondents used Android devices whereas 69\% owned iPhones. 


\subsection{Materials}

Measurements of the variables used in this research were based, first, on the study of actual smartphone use inside and outside the classroom and, second, on a survey concerning student preferences for smartphone use in an educational setting.

The first part of the study spanned two academic terms (fall 2016 and spring 2017) and assumed that students actively used their smartphone in their Writing and Information Literacy class. This mostly consisted of reading short texts on the phone screen, sharing materials, note-taking, taking photos of the whiteboard and/or smartboard, recording students' oral presentations, sharing homework assignments, reminding classmates about important deadlines, and so on. To facilitate the sharing process, a WhatsApp group was created among students in the same Writing and Information Literacy group. Note that the course instructor was not part of the WhatsApp group, but contacted students via the university platform.

The first part of the survey was accompanied by the teachers' notes for their observation checklist, making it possible to specify the smartphone functions welcomed by students and the activities they willingly implemented in class. This was the first experiment of this nature, as students had always been prohibited from using smartphones in class in the past.

The second part of the study was based on an online questionnaire at the end of the second term to survey students' opinions regarding the use of smartphones in their Writing and Information Literacy classes. The questionnaire was divided into five sections. The first section covered general information and was intended to collect demographic information from respondents. The second concerned four items to determine why students used their smartphone. The third targeted mobile applications widely used by the students. The fourth focused on smartphone effectiveness for reading and writing (note-taking) tasks. Finally, the fifth section explo- red what students thought about using smartphones in the modern classroom. In total, the survey posed 23 questions ranging from multiple-choice and open-ended questions to Likert-scale questions with a five-point agreement scale, from complete disagreement to complete agreement. Furthermore, the second section made broad use of the frequency scale of (1) never, (2) rarely, (3) sometimes, (4) often, and (5) always.

\subsection{Procedure}

As previously stated, over two academic terms (fall 2016 and spring 2017), 204 ADA University students from eight Writing and Information Literacy sections were asked to actively use their smartphone during class, with emphasis on such phone functions as "take a photo (of the paper)," "take a video (of the presentation, etc.)," "take some quick notes," "read a short text from your smartphone," "use the zoom function to see the board more clearly" (for students with poor eyesight), "search for relevant information using Google," and "check/ consult the university library page." Additionally, after the class, each group of students could communicate with one another to arrange class-related meetings or provide clarifications to other students who needed help. To make communication quicker and more effective, students in each writing section (each consisting of about 22 students) were asked to create a WhatsApp group called "Writing". This allowed them to access the group with a single tap. Moreover, to save paper, the instructor would ask a student to take a photo of a single hard copy of learning materials and circulate it to other students via WhatsApp. Examples include short texts with 5 to 10 lines for students to read, then critically analyze in writing, or a short activity that might take 5 to 7 minutes. Most students liked not having to hide their mobile devices for the first time.

The study ended with a survey at the end of the academic year. Participants were asked to fill out an online questionnaire designed to sound out the students' opinion about their new experiences. 
The study has several limitations. Due to the small number of students selected from a single university, the results should be considered illustrative rather than conclusive. Furthermore, this pilot study involved very few smartphone functions, including a unique WhatsApp application.

\section{Results and discussion}

The results show that $99.5 \%$ of respondents used smartphones; among these, $69 \%$ used iPhones (mostly with the IOS operating system), 29\% used devices with the Android operating system, and another $2 \%$ used another smartphone operating system. Moreover, the survey shows that among the range of available portable devices, smartphones were widely favoured for the following reasons (see Table 1): they are light (61.8\%); they are easy to use while in transit (60\%); their small size makes them easy to take everywhere (76.6\%). Additionally, one-quarter (24\%) of the respondents said that due to their poor eyesight, they frequently use a zoom function to better see the whiteboard and/or smartboard at a distance.

\section{Table 1}

Reasons why students prefer smartphones to other portable devices

\begin{tabular}{lc}
\hline \hline Smartphones are light & $61.8 \%$ \\
\hline $\begin{array}{l}\text { Smartphones are small enough to take } \\
\text { everywhere }\end{array}$ & $76.6 \%$ \\
$\begin{array}{l}\text { Smartphones usually require no password to } \\
\text { open }\end{array}$ & $16.8 \%$ \\
$\begin{array}{l}\text { Smartphones keep their charge longer than } \\
\text { other portable devices }\end{array}$ & $13.3 \%$ \\
\hline $\begin{array}{l}\text { Smartphones are easy to use while in transit } \\
\text { Smartphones have a zoom function }\end{array}$ & $60 \%$ \\
\hline \hline
\end{tabular}

Based on the students' positive attitude to smartphone use in their daily life, we wanted to determine how often they checked their phone every hour. Nearly half the respondents (49.26\%) admitted checking their smartphone every 10 minutes, whereas $33 \%$ of the students did so every 30 minu- tes. Only 35 students (17.24\%) said they checked it once per hour.

Table 2 shows the most popular reasons for smartphone use. Hence, the most frequently used smartphone function is "communication," with $92.12 \%$ of respondents reporting that contacting (texting) friends and groupmates works best via smartphone and phone applications. The next most popular smartphone function is the availability of a search engine (74.88\%) like Google, Yahoo, Noodle or Yandex. Finally, the third most popular reason for smartphone use is "educational purposes" (70.1\%), which consists of using the device for reading, notetaking, sharing materials, and so on. More than half the respondents (67.4\%) identified hobbies and entertainment, contacting family members $(66.01 \%)$, and social issues $(53.7 \%)$ as among their preferred smartphone uses. Surprisingly, a lower proportion of students uses their smartphone for scheduling (only $32.84 \%$ ), which may say something about their time management skills. In addition, the observations show that more than one-third of students frequently use functions like the calendar and alarm clock. Finally, "games" and "shopping" are the least popular uses $(19.7 \%$ and $5.47 \%$, respectively), suggesting that students may be more absorbed in classroom lessons and active educational life.

\section{Table 2}

The most popular reasons for smartphone use by students:

\begin{tabular}{lc}
\hline \hline \multicolumn{1}{c}{ Reason for smartphone use } & $\begin{array}{c}\text { Frequency as a } \\
\text { Percentage }\end{array}$ \\
\hline Social issues & $53.7 \%$ \\
Communication & $92.12 \%$ \\
Shopping & $5.47 \%$ \\
Education & $70.1 \%$ \\
Hobbies and entertainment & $67.48 \%$ \\
Games & $19.7 \%$ \\
Search engine & $74.88 \%$ \\
To contact family & $66.01 \%$ \\
To arrange schedule & $32.84 \%$ \\
\hline \hline
\end{tabular}


Because $70 \%$ of the respondents used their smartphone for educational purposes, the next question was designed to determine the key activities necessary to achieve academic goals. Thus, out of six suggested smartphone functions with the potential to facilitate learners' academic life, the most popular are "e-mail checking" (87.53\%) and "use of search engines" (83.9\%). Other favoured activities are "use of dictionary" (73.04\%) and "note-taking" (45.77\%). Finally, nearly one-third of respondents believed their smartphone can be very helpful for consulting the "online university library" $(24.26 \%)$ and for "rehearsing short presentations" (21.7\%) before the actual class presentation. Additionally, many students found handheld smartphones to be particularly useful while in transit, a time when they can review pre-class assignments or rehearse presentations on a crowded bus. As regards the use of smartphones for the Writing and Information Literacy class in particular, the majority of respondents admitted they always used their smartphone to "consult the dictionary" $(66.9 \%)$ and "read short texts distributed by the teacher" (64.5\%). An equal number of students report using their smartphone to "take photos of the smartboard" $(66.6 \%)$ and the whiteboard (66.6\%). Finally, nearly $64 \%$ of respondents used it to "consult Google" to find the academic information needed for the course. Conversely, most learners $(72.9 \%)$ never recorded the teachers' voice in their writing class. This is mostly because few teachers give students permission to record their classes. Furthermore, one limitation of the experiment is that the instructor forbade video and audio recordings of class teaching. Unexpectedly, many respondents $(48.6 \%)$ admitted they were disinclined to use their smartphone for note-taking; instead, they preferred to take photos of the whiteboard (with teachers' notes) or smartboard where teachers showed lesson-related slides. Additionally, based on class observations during the experiment, it was obvious that many students disliked taking notes with their mobile phones and felt uncomfortable carrying out writing assignments on a smartphone. For example, students received an electronic text (passage) to be paraphrased or were asked to place paragraphs in a logical order. According to observations, the most popular smartphone functions among students were: taking photos of the whiteboard and/or smartboard, consulting the dictionary, and reading short texts from the screen.

Since most smartphones suggest a wide variety of applications for download and WhatsApp is among the most popular ones with students at ADA University, we wished to clarify how useful the app could be for the Writing and Information Literacy class. In point of fact, $98 \%$ of respondents admitted they frequently use WhatsApp. A small minority (2\%) said they preferred the Dropbox, Facebook Messenger, or Telegram applications. In regard to WhatsApp (see Table 3), 91.3\% of respondents reported that they frequently chat with their groupmates. Moreover, $80.8 \%$ of the students often asked groupmates and friends about homework. Consequently, over $81 \%$ of respondents said they willingly share materials and class notes with their groupmates via WhatsApp messenger. More than $37 \%$ - mostly inattentive students or frequent absentees-admitted to frequently texting their friends for clarifications of all kinds. Finally, 78.4\% of the students said they always let their classmates know about changes during the term (e.g., change of classroom, upcoming deadlines, grade postings, class cancellations, and make-up classes).

\section{Table 3}

The use of WhatsApp for academic purposes

\begin{tabular}{ll}
\hline \hline Chat with groupmates & $91.6 \%$ \\
Ask about homework & $80.8 \%$ \\
Share materials & $81.3 \%$ \\
$\begin{array}{l}\text { Inform other students about any } \\
\text { changes related to the writing class }\end{array}$ & $78.4 \%$ \\
Ask for clarification & $37.6 \%$ \\
\hline \hline
\end{tabular}

Finally, the observations show that many survey participants do enjoy using WhatsApp to contact their peers for academic purposes.

Today, many agree that smartphone screens can replace paper books and copybooks. Thus, more than $14 \%$ of the students said they always read 
from their phones, versus nearly $62 \%$ who read from their smartphone only if there is no hard copy of the text. Additionally, students believe that reading from their smartphone is comfortable because, first of all, they always have their phone with them $(45.1 \%)$; reading from their phone saves trees (20.1\%); reading from their phone saves financial resources $(9.8 \%)$, i.e., there is no need to spend money on paper books and photocopies; and, finally, $8.8 \%$ of the students think that reading from the smartphone screen is easy.

In contrast, about one-quarter of the respondents said they never use their phone to take notes, giving such explanations as: "it's hard to take notes with smartphones because they don't have functions like graphs, charts or tables." Furthermore, some students believe that taking notes with smartphones is time consuming because they have poor typing skills. Finally, some students think notes can be mistakenly deleted from the phone. Yet nearly half the respondents admit to taking notes with their smartphone when they have no paper. Conversely, $65.2 \%$ of the students believe that taking notes on a smartphone is quick and easy. Above all, some students say that paper can often be lost, but "your phone goes with you almost everywhere, and you can check it anytime."

Finally, more than $72 \%$ of students believe that smartphones should be used in modern academic writing classes. To determine the statistically significant difference between the percentage of students who believe that smartphones should be used in the modern classroom and those who state they should never be used in this way, we calculated the $p$-value claiming that the difference in percentage will be considered statistically highly significant with a p-value of less than 0.0001 . Thus, the analysis shows that when comparing "yes" and "no" answers, the $p$-value is equal to 0.0000 , indicating a substantial difference in student opinions on this issue (see Table 4).
Table 4

Student opinions on whether smartphones should be used in the modern classroom

I believe smartphones should be used in the modern classroom

Yes $\quad 72.5 \%$

No $\quad 27.5 \% \quad P$-value $=0.0000$

- $\quad$ Students cite a number of reasons why they believe smartphones should be used in modern writing classes (see the list below).

- Smartphones are a quick and easy way to share information.

- My smartphone goes everywhere with me.

- Smartphones provide quick access to video and audio recordings.

- Smartphones are light.

- It is quick and easy to take photos of the whiteboard or smartboard (rather than taking notes on a paper).

- The use of smartphones saves trees.

- Smartphones provide easy access to all sorts of online information (i.e., quick access to online and electronic materials).

- Smartphones increase student motivation.

- Smartphones are an effective means of communication for academic and personal purposes.

- Smartphones are a quick way to take notes.

- Smartphones provide quick access to e-mail.

- Smartphones provide quick access to digital texts and materials, etc.

- Smartphones provide quick access to the university library.

The list identifies a number of important smartphone functions - more specifically, those used in class during the experiment. In particular, the students believe that smartphone use saves trees. Prior to the experiment, students in previous years were given paper sheets with several lines of text for an educational activity lasting three to four minutes. At the 
end of the lesson, these papers would be thrown away. If every teacher wasted this much paper just to fill five to ten minutes of class time, it will lead to unreasonable paper consumption. With the appearance of digital technology, it is now possible to substitute paper with digital screens.

On the contrary, more than one-quarter of the students believe there is no need to use smartphones for educational purposes, i.e., that classes can easily be conducted without modern mobile technology. The most common reasons the respondents cited for their belief that smartphones should be prohibited in the modern classroom are:

- Smartphones can distract students.

- Handwritten notes are easier for memorizing information.

- Some smartphone notification sounds (used by such applications as Facebook, Viber, and WhatsApp) can distract students while they are reading a text on a smartphone.

- $\quad$ Some students may pretend to be using smartphones for educational purposes while actually playing games or chatting with friends.

- Smartphone screens are a bit small for reading purposes.

- Smartphones make students lazier (in terms of carrying notebooks and pens, writing by hand, etc.).

- Smartphones are bad for health.

Considered separately, these reasons prove questionable. For instance, while smartphones can certainly distract students with alerts, these notifications can be turned off (for example, using airplane mode). Likewise, it is also true that students can fake smartphone use for educational purposes and instead be gaming or watching videos. However, a skillful and experienced teacher can make use of the situation and instill in students qualities like responsibility, team spirit and dedication to learning. As a result, students may feel self-conscious if they use smartphones for other than academic ends. As regards note-taking, this research did not oblige learners to use smartphones instead of paper; thus, those accustomed to a traditional penand-paper approach to note-taking could continue to do so. The same rule applies to students who find their smartphone screen too small and uncomfortable for reading: they can easily use their laptops or iPads for this task. The purpose of this paper is not to eradicate "old classroom ways" but to show that smartphones can be useful in the modern classroom and can even be an effective complement and facilitating tool.

Overall, on the basis of the above lists, we can conclude that there are many reasons to consider smartphones a good means of facilitating modern classroom teaching.

\section{Conclusion}

The results of this study demonstrate that most students at ADA University use smartphones as well as the WhatsApp application. Handheld smartphones are commonly used for socializing, communication and academic purposes. Many students believe that smartphones facilitate their learning process through quick access to online dictionaries, university library pages, universal search engines, and personal e-mails. Similarly, smartphone functions like note-taking, on-screen reading, taking photos of the whiteboard and/or smartboard, and recording oral presentations can contribute to increased learning productivity, boosting student motivation. Accessibility is mainly a function of smartphone characteristics: they are lightweight, pocket-sized, and mobile. Moreover, Wi-Fi connectivity and the availability of the WhatsApp application in particular make it easy for students to stay in touch. This strengthens students' peer support, communication skills, and capacity for team work. In addition, many students believe that class communication can also be facilitated by other applications similar to WhatsApp, such as Viber, Telegram, and even Facebook Messenger. Teachers may observe that creating a WhatsApp group helps their students by saving time when materials are distributed and informing them of classroom changes or other last-minute situations they need to be told about quickly. 
Because the Writing and Information Literacy class involves reading, writing, sharing materials, recording oral presentations and other similar techniques, it was an ideal setting for the study and emphasized the unprecedented role of smartphone use in the modern classroom. Above all, the data analysis shows that although one-quarter of respondents suggested that smartphones should not be used in class today for the reasons identified earlier, many students are convinced that this technology should become part of every classroom's technological devices. Once learners understand that smartphones can facilitate learning, it will be hard for them to put away their phones. Hence, instructors should move toward "legalizing" the use of smartphones in the classroom rather than wondering if students are playing games or "passing notes under the desk." In other words, allowing students to use their smartphone for academic purposes will help teachers better control the situation. Note that in terms of improving the learning process, smartphones do not provide any additional knowledge: they only facilitate teaching and learning, which enhances student motivation and interest in the class.

Finally, this research paper may push current teachers and instructors in all fields, particularly in writing and information literacy, to reconsider their negative views on smartphone use in the modern classroom. This will lead to certain changes in teaching methodology and in classroom management. Remember, the only constant is change! Teaching methodology is always undergoing some form of transformation resulting in a variety of innovations. The new methodology will not only require new classroom instructions or techniques (for sharing materials or note-taking), but will require teachers to be more skillful in controlling their students' smartphone use for academic purposes. Finally, since we live at a time when new technologies are ubiquitous in all aspects of our lives (including education), educators must stay current to keep pace with these changes and meet the demands of our era.

\subsection{Pedagogical implications}

The ultimate goal of this research is to show that smartphones should be considered more "friend" than "foe" in the classroom. Statistics (Mammadova, 2014) derived from classroom observations show that many universities in Azerbaijan lack a high-quality wireless Internet environment-in most cases, students have no university Wi-Fi connection at all because the institution deems they should not be using smartphones (or the Internet) in class. As for teachers, they should consider making smartphones part of the teaching and learning processes both inside and outside the classroom. This would involve reconsidering paper-based activities and taking a digital approach to classroom presentations and practices. Moreover, teachers should urge school administrators to provide Wi-Fi access for everyone involved in teaching and learning. In doing so, schools can stop the tug-of-war with student smartphone use and instead foster a new "wireless teaching era."

\section{References}

Agbatogun, A. O. (2013). Interactive digital technologies' use in Southwest Nigerian universities. Educational Technology Research and Development, 61(2), 333-357. doi:10.1007/s11423-012-9282-1

Dukic, Z., Chiu, K. W. D., \& Lo, P. (2015). How useful are smartphones for learning? Perceptions and practices of library and information science students from Hong Kong and Japan. Library Hi Tech, 33(4), 545-561. doi:10.1108/LHT-02-2015-0015

Langan, D., Schott, N., Wykes, T., Szeto, J., Kolpin, S., Lopez, C., \& Smith, N. (2016). Students' use of personal technologies in the university classroom: analysis the perceptions of the digital generation. Technology, Pedagogy and Education, 25(1), 101-117. doi:10.1080/1475939X.2015.1120684

Mammadova, T. (2014). A four-stage assessment of AUL (Azerbaijan University of Languages) teachers' abilities to adapt innovative teaching approaches. Encuentro, (23), 72-88. Retrieved from Biblioteca Digital Universidad de Alacalá website: http://ebuah.uah.es 
Morse, T. E., \& Crowe, M. W. (2012). Is assistive technology or universal design a more effective method of technology integration for students with disabilities? In P. K. Brady (Ed.), Technology in Schools (Debating issues in American Education, vol. 10) (pp.1-16). Los Angeles, CA: Sage.

Mostert, M., \& Quinn, L. (2009). Using ICTs in teaching and learning: Reflections on professional development of academic staff. International Journal of Education and Development using Information and Communication Technology, 5(5). Retrieved from http://ijedict.dec.uwi.edu

Park, S. Y., Nam, M.-W., \& Cha, S.-B. (2012). University students' behavioral intention to use mobile learning: Evaluating the technology acceptance model. British Journal of Educational Technology, 43(4), 592-605. doi:10.1111/j.1467-8535.2011.01229.x

Reese Bomhold, C. (2013). Educational use of smart phone technology: A survey of mobile phone application use by undergraduate university students. Program, 47(4), 424436. doi:10.1108/PROG-01-2013-0003

Sauers, N., \& Kruse, J. W. (2012). Do pocket assistive technologies, such as the iPod, iPhone, and iPad, provide mainly educational benefits or distractions to students in today's schools? In P. K. Brady (Ed.), Technology in Schools (Debating issues in American Education, vol. 10) (pp. 32-41). Los Angeles, CA: Sage.

Shahriza Abdul Karim, N., Oyebisi, I. O., \& Mahmud, M. (2010). Mobile phone appropriation of students and staff at an institution of higher learning. Campus-Wide Information Systems, 24(4), 263-276. doi:10.1108/10650 741011073806

Wabwoba, F., Omieno, K. K., Simiyiu, C. N., \& Sisungo, Z. W. (2011). The role of wireless technologies in taking education to rural villages in developing countries. International Journal of Information and Communication Technology Research, 1(7), 300-305. Retrieved from http://esjournals.org/journaloftechnology 